\title{
Effect of different nickel-titanium rotary files on dentinal crack formation during root canal preparation in primary molars: a laboratory study
}

\author{
Taha Özyürek, ${ }^{1}$ Gülşah Uslu, ${ }^{1}$ Koray Yılmaz ${ }^{2}$ \\ 'Department of Endodontics, Ondokuz Mayıs University Faculty of Dentistry, Samsun, Turkey \\ ${ }^{2}$ Department of Endodontics, Çorum Oral and Health Care Center, Çorum, Turkey
}

\begin{abstract}
Objective: To compare the dentinal cracks caused by Reciproc, WaveOne Gold, and ProTaper Next NiTi rotary file systems during root canal preparation in primary molars.

Methods: Eighty mandibular primary molars with two separate and straight mesial canals were included in this study. The teeth were randomly divided into the following four groups: control, Reciproc, WaveOne Gold, and ProTaper Next. The 80 specimens were cut perpendicular to the tooth axis at 3-, 6-, and 9-mm distance from the apex, and using stereomicroscope, they were examined to determine the presence of any crack. Data were statistically analyzed by chi-square test using the SPSS 21.0 software.

Results: Statistically significantly more dentinal cracks were found in the Reciproc, WaveOne Gold, and ProTaper Next groups than in the control group $(p<.05)$. A statistically lesser dentinal cracks were observed in the WaveOne Gold and ProTaper Next groups than in the Reciproc group in terms of observed total dentin crack $(p<.05)$. More dentinal cracks in the apical region were observed in the Reciproc group than in the WaveOne Gold and ProTaper Next groups $(p<.05)$.
\end{abstract}

Conclusion: Within the limitations of the study, statistically significantly more dentinal cracks were observed in the tested nickel-titanium file system groups than in the control group.

Keywords: Dentinal crack; primary teeth; ProTaper Next; Reciproc; WaveOne Gold.

$\mathrm{R}$ oot canal treatment of primary teeth offers advantages such as maintaining teeth until physiological exfoliation and ensuring phonation and aesthetic. ${ }^{[1,2]}$ The objective of root canal treatment of primary teeth is to remove most of the infected material and contaminated dentin by shaping the root canal system using endodontic instruments, to ensure disinfection of the root canal, and to hermetically obturate the canal. ${ }^{[3,4]}$ The mechanical preparation of root canals of primary teeth might be performed using manual and nickel-titanium (NiTi) rotary files. ${ }^{[5]}$ When manually preparing the root canal, the incidence of complications such as zip formation, perforation, apical debris extrusion, and file fractures increases. ${ }^{[6]}$ Root canal preparation using NiTi rotary devices takes less time than that using manual files. ${ }^{[7]}$ Rapid preparation, which can be performed using NiTi rotary instruments without compromising on quality reliability, allows the completion of root canal treatment in pedi-

Correspondence: Dr. Taha Özyürek. Ondokuz Mayıs Üniversitesi Diş Hekimliği Fakültesi, Endodonti Anabilim Dalı, Samsun, Turkey.

Tel: +90 362 - 3121919 e-mail: tahaozyurek@hotmail.com

Submitted: March 30, 2017 Accepted: June 20, 2017 
atric dentistry before the patient and physician become fatigued.$^{[8]}$

Various NiTi rotary file systems are commercially available for root canal preparation purposes. ProTaper Next (PTN; Dentsply Maillefer, Ballaigues, Switzerland) is a file system that has horizontal square cross-sections and is made of M-Wire alloy. The single-file systems made of M-Wire alloy and has reciprocation motion became widely popular at the present time. Reciproc (RPC; VDW, Munich, Germany) and WaveOne (WO; Dentsply Maillefer, Baillagues, Switzerland) files are well-known single-file NiTi systems with reciprocating motion and have the same tip diameter and taper angle (size 25 tip and size 0.08 taper). ${ }^{[9]}$ The tapers are fixed at $3 \mathrm{~mm}$ from the apex of the files and decrease in the middle and coronal sections. ${ }^{[10]}$ The RPC file is S-shaped with two cutting edges, and the WO file features a modified convex triangular crosssection in the apex, with a convex triangular cross-section in the middle and coronal sections. ${ }^{[11,12]}$ Both RPC and WO files are made of M-Wire alloy. ${ }^{[13]}$

The WO NiTi single-file system was recently modified to WO Gold (WOG). While maintaining the reciprocation movement of file, its cross-section, dimensions, and geometry were changed. The cross-section of the file was altered to a parallelogram with two cutting edges. Moreover, the off-center design that PTN files have is also used in WOG files. The most significant change in files is the production utilizing Gold heat treatment method. Gold heat treatment is based on reversing the M-Wire technology, which employs pre-production heat treatment and by heating the file after production and then slowly cooling it. The manufacturer company claims that this new heat treatment increases the flexibility of files. ${ }^{[14]}$

The root canal preparation may cause dentinal stress and consequently dentinal cracks. The emerging dentinal fractures may transform into vertical root fractures under functional loads. ${ }^{[2]}$ The physical and mechanical properties of NiTi rotary file systems may affect the incidence of cracks on the dentinal surface. ${ }^{[3]}$ Many studies have examined dentinal crack formation caused by NiTi files during root canal preparation in permanent teeth. ${ }^{[15,16]} \mathrm{A}$ comprehensive literature review revealed that no study examined the dentinal crack in primary molars, which were caused by NiTi rotary files. Therefore, this study aimed to compare the dentinal crack caused by RPC, WOG, and PTN NiTi rotary file systems during root canal preparation in primary molars. The null hypothesis of the study was that there was no difference among the tested NiTi rotary file systems in terms of the frequency of dentinal cracks.

\section{Materials and methods}

\section{Specimen selection}

In this study, 80 primary mandibular molars that were extracted owing to periapical pathology and preventive orthodontic treatment were used. Bucco-lingually and mesiodistally radiographs of the teeth were taken to rule out any aberrant canal morphology and to confirm two separate mesial canals with $<5^{\circ}$ of canal curvature. ${ }^{[17]}$ Soft and hard tissues around the teeth were mechanically removed using a periodontal curette. The selected teeth were kept in distilled water at $4^{\circ} \mathrm{C}$ for the experimental procedures.

The roots of teeth were wrapped with aluminum foil and then embedded into acrylic resin (Imicryl, Konya, Turkey) ${ }^{\left[{ }^{[18]}\right.}$ After setting the teeth in acrylic resin, they were taken out from the resin, and the foils were removed. To simulate the periodontal ligament, the resin blocks were filled with viscous silicon impression material (Express XT Light Body Quick; 3M ESPE, Neuss, Germany), and the specimens were then placed into the resin blocks again.

\section{Root canal preparation}

The teeth were randomly divided into four groups $(n=20$ teeth/group). In experimental groups, the canals of teeth were penetrated using \#10 K-file (Dentsply Maillefer) until the tip of file is seen from the apex. The working length was set to $1 \mathrm{~mm}$ shorter than this length. The glide path was created ensuring an apical diameter of $0.20 \mathrm{~mm}$. Then, the following procedures were performed.

\section{Group 1: RPC}

In this group, according to the manufacturer's instruction, root canals of the teeth were prepared using the RPC R25 (25/.08) file and the torque-controlled endodontic motor (VDW Reciproc GOLD; VDW) in the "Reciproc ALL" program.

\section{Group 2: WOG}

In this group, according to the manufacturer's instruction, root canals of the teeth were prepared using the WOG Primary $(25 / .07)$ file and the torque-controlled endodontic motor in the "WaveOne ALL" program.

\section{Group 3: PTN}

In this group, according to the manufacturer's instruction, root canals of the teeth were prepared using the PTN XI $(17 / .04)$ and X2 (25/.06) files at $300 \mathrm{rpm}$ and $3 \mathrm{Ncm}$ torque and the torque-controlled endodontic motor (XSmart; Dentsply Maillefer). 


\section{Group 4: Negative control}

In this group, the teeth were left unprepared and maintained as the negative control group.

In the experimental groups, $20 \mathrm{ml}$ of $1 \%$ sodium hypochlorite $(\mathrm{NaOCl})$ was used during the preparation. The entire procedure was executed by the same endodontist who had 5 years of experience.

\section{Sectioning and microscopic examination}

Using a water-cooled, low-speed saw (Isomet; Buehler Ltd, Lake Bluff, IL, USA), the roots of 80 teeth were cut perpendicular to the tooth axis at 3-, 6-, and 9-mm distance from the apex, and three slices were obtained from each specimen. The digital images of the obtained slices were taken using a digital camera connected to a stereomicroscope (Olympus BX43, Olympus Co., Tokyo, Japan) with $\mathrm{x} 25$ magnification. In total, 240 digital images (60 images/group) were examined for the presence of any crack. To define crack formation, two different categories were established (i.e., "no crack" and "crack") to avoid confusing descriptions of root cracks. "No crack" was defined as root dentin without cracks or craze lines either at the internal surface of the root canal wall or the external surface of the root. "Crack" was defined as all lines observed on the slice that either extended from the root canal lumen to the dentin or from the outer root surface to the dentin (Figure 1). ${ }^{[19]}$

\section{Statistical analysis}

To assess the intergroup incidence of dentinal cracks, chisquare test was performed. The level of statistical significance was set at $5 \%$. Statistical analyses were performed using the SPSS 21.0 (IBM-SPSS Inc., Chicago, IL, USA) software.

\section{Results}

In this study, 240 tooth slices were examined. The distribution of dentinal cracks caused by the tested NiTi file systems among the apical, middle, and coronal regions is

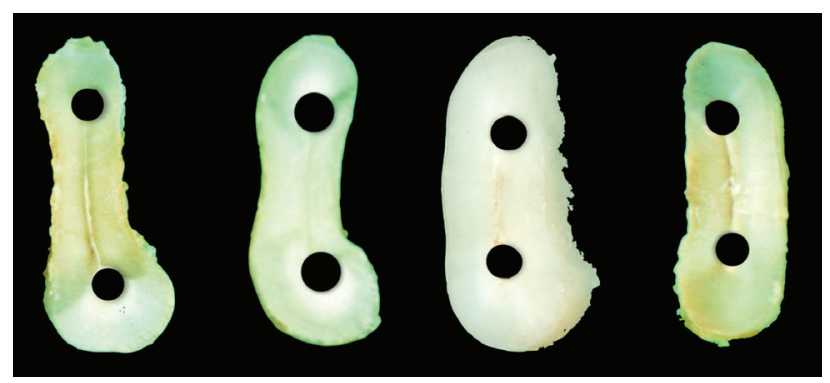

Fig. 1. The specimens showing dentinal defects after root canal preparation.

presented in Table 1. Statistically significantly more dentinal cracks were observed in the RPC, PTN, and WOG groups than in the control group in terms of the total number of dentinal crack $(\mathrm{p}<.05)$. Statistically lesser dentinal cracks were observed in the WOG and PTN groups than in the RPC groups in terms of observed total dentin crack $(\mathrm{p}<.05)$. More dentinal cracks in the apical region were observed in the RPC group than in the WOG and PTN groups $(\mathrm{p}<.05)$.

\section{Discussion}

The vertical root fracture in endodontically treated teeth is an undesired condition and usually results in the extraction of involved teeth. ${ }^{[20]}$ Thus, this study aimed to examine dentinal cracks caused by RPC, WOG, and PTN NiTi rotary file systems, which have different kinematics, during root canal preparation in primary molars. According to the study results, the amount of dentinal cracks observed was statistically higher in the RPC, WOG, and PTN groups than in the control group. Thus, the null hypothesis was rejected.

Mandibular primary molar teeth were used in this study. Before the study, the teeth were examined using a stereomicroscope for the presence of any fracture or crack. However, although there may be cracks in some teeth, they may not be externally observed. The absence of any dentinal crack in the negative control group indicated that the teeth were free of cracks and is in corroboration with that reported in other studies. ${ }^{[21,22]}$

Table 1. The number and percentage of tooth slices with defects at each region $(n=20)$

\begin{tabular}{lcccc} 
Group & $\begin{array}{c}\mathbf{3} \mathbf{~ m m} \\
\mathbf{n}(\%)\end{array}$ & $\begin{array}{c}\mathbf{6} \mathbf{~ m m} \\
\mathbf{n}(\%)\end{array}$ & $\begin{array}{c}\mathbf{9} \mathbf{~ m m} \\
\mathbf{n}(\%)\end{array}$ & $\begin{array}{c}\text { Total number of specimens with defects } \\
\mathbf{n}(\%)\end{array}$ \\
\hline Control & $0(0)^{\mathrm{a}}$ & $0(0)^{\mathrm{a}}$ & $0(0)^{\mathrm{a}}$ & $0(0)^{\mathrm{a}}$ \\
Reciproc & $8(40)^{\mathrm{b}}$ & $11(55)^{\mathrm{b}}$ & $8(40)^{\mathrm{b}}$ & $15(75)^{\mathrm{b}}$ \\
WaveOne Gold & $5(25)^{\mathrm{c}}$ & $10(50)^{\mathrm{b}}$ & $7(35)^{\mathrm{b}}$ & $10(50)^{\mathrm{c}}$ \\
ProTaper Next & $4(20)^{\mathrm{c}}$ & $8(40)^{\mathrm{b}}$ & $7(35)^{\mathrm{b}}$ & $10(50)^{\mathrm{c}}$ \\
P value & $<.05$ & $<.05$ & $<.05$ & $<.05$ \\
\hline
\end{tabular}

*Different superscript letter indicates statistically difference at $\mathrm{p}=.05$. 
In this study, the teeth were perpendicularly cut along the long axis and analyzed using a stereomicroscope. Although the slicing method damaged specimens, no dentinal crack was observed on the specimen in the negative control group. Shemesh et al. ${ }^{[23]}$ examined the efficiency of optical coherence tomography in detecting vertical root fractures. Researchers reported that optical coherence tomography was useful in detecting vertical root fractures and that it successfully showed the point at which vertical root fractures were localized. De-Deus et al. ${ }^{[24]}$ examined dentinal cracks caused by various NiTi file systems using computed microtomography. Researchers reported that computed microtomography is a very useful and conservative method for detecting dentinal cracks. However, the capability of computed microtomography in detecting small dentinal cracks remains unclear. If the resolution of computed microtomography is larger than that of the dentinal crack, then it cannot detect the crack. Thus, the slicing method was used in this study, similar to previous studies. ${ }^{[22,25,26]}$

NiTi file manufacturers generally recommend using the file on a single tooth. Thus, in this study, to prevent the effects of file deformation on the results, a new set of file was used to prepare only one sample's root canals (two canals). Previous studies have reported that high concentrations of $\mathrm{NaOCl}$ solution decreased the elastic module and hardness level of dentin. ${ }^{[27,28]}$ In this study, $1 \% \mathrm{NaOCl}$ solution was used as the irrigation solution for protecting the microstructure of dentine to ensure that the dentinal cracks were mainly related to the mechanical preparation.

Because no study has examined dentinal cracks caused by NiTi rotary file systems during root canal preparation in primary molars, the results of this study cannot be directly compared with those of other studies. Previous studies stated that the characteristics of NiTi files, such as the tip design, cross-section, or variable or constant taper, might have an effect on the formation of dentinal cracks. ${ }^{[9,21]}$ Moreover, files with a high taper caused higher stress levels on canal walls. ${ }^{[29]}$ In corroboration with this finding, our study revealed that the RPC file with a high taper caused statistically significantly more dentin cracks. Furthermore, despite having the same movement kinematics, WOG files caused statistically significantly less dentin cracks than RPC files; this is believed to originate from the low taper of WOG files, in addition to the use of gold alloy, which has no shape memory, in the manufacturing process of WOG files.

According to our study results, no statistically significant difference was found between the PTN and WOG files in terms of causing dentin cracks. PTN files have a rectangular cross-section, whereas WOG files have a simi- lar parallelogram cross-section. Moreover, both PTN and WOG files have an off-center design that allows dentinal debris to move coronally by decreasing the contact with canal walls during preparation. These similar design characteristics are believed to influence the efficiencies in causing dentin cracks. In parallel with our study results, Karataş et al. ${ }^{[30]}$ reported that there was no statistically singificant difference between PTN and WO files in terms of creating dentin cracks on mandibular incisor teeth.

Although simulating the clinical conditions in the laboratory environment is critical, external factors such as the storage of teeth after extraction until slicing might affect study results, particularly in studies that examine the mechanical properties of teeth. ${ }^{[19]}$ Considering the anatomical, histological, and chemical differences between permanent and primary dentitions, such as increased mineralization of permanent teeth and morphsological changes owing to the presence of physiological or pathological root resorption, results obtained in permanent teeth cannot be transposed to primary teeth. ${ }^{[8]}$

\section{Conclusion}

Within the limitations of this study, statistically significantly more dentinal cracks were observed in the RPC, WOG, and PTN groups than in the negative control group. In addition, more dentinal cracks were observed in the RPC group than in the WOG and PTN groups.

\section{Acknowledgments}

The author does not have any conflicts of interest related to this study.

Conflict of interest: None declared.

\section{References}

1. Bodur H, Odabaş M, Tulunoğlu O, Tinaz AC. Accuracy of two different apex locators in primary teeth with and without root resorption. Clin Oral Investig 2008;12:137-41.

2. Leonardo MR, Silva LA, Nelson-Filho P, Silva RA, Raffaini MS. Ex vivo evaluation of the accuracy of two electronic apex locators during root canal length determination in primary teeth. Int Endod J 2008;41:317-21. [CrossRef]

3. Kalra N, Sushma K, Mahapatra GK. Changes in developing succedaneous teeth as a consequence of infected deciduous molars. J Indian Soc Pedod Prev Dent 2000;18:90-4.

4. Cordeiro MM, Rocha MJ. The effects of periradicular inflamation and infection on a primary tooth and permanent successor. J Clin Pediatr Dent 2005;29:193-200. [CrossRef]

5. Barr ES, Kleier DJ, Barr NV. Use of nickel-titanium rotary files for root canal preparation in primary teeth. Pediatr Dent 2000;22:77-8. 
6. Silva LA, Leonardo MR, Nelson-Filho P, Tanomaru JM. Comparison of rotary and manual instrumentation techniques on cleaning capacity and instrumentation time in deciduous molars. J Dent Child (Chic) 2004;71:45-7.

7. Guelzow A, Stamm O, Martus P, Kielbassa AM. Comparative study of six rotary nickel-titanium systems and hand instrumentation for root canal preparation. Int Endod J 2005;38:743-52. [CrossRef]

8. Kummer TR, Calvo MC, Cordeiro MM, de Sousa Vieira R, de Carvalho Rocha MJ. Ex vivo study of manual and rotary instrumentation techniques in human primary teeth. Oral Surg Oral Med Oral Pathol Oral Radiol Endod 2008;105:e84-92. [CrossRef]

9. Bürklein $\mathrm{S}$, Tsotsis $\mathrm{P}$, Schäfer E. Incidence of dentinal defects after root canal preparation: reciprocating versus rotary instrumentation. J Endod 2013;39:501-4. [CrossRef]

10. Plotino G, Grande NM, Testarelli L, Gambarini G. Cyclic fatigue of Reciproc and WaveOne reciprocating instruments. Int Endod J 2012;45:614-8. [CrossRef]

11. Wolcott S, Wolcott J, Ishley D, Kennedy W, Johnson S, Minnich S, et al. Separation incidence of protaper rotary instruments: a large cohort clinical evaluation. J Endod 2006;32:1139-41. [CrossRef]

12. Ruddle CJ. Canal preparation: single-file shaping technique. Dent Today 2012;31:124-9.

13. Elnaghy AM, Elsaka SE. Torsion and bending properties of OneShape and WaveOne instruments. J Endod 2015;41:544-7. [CrossRef]

14. Brochure Wave One Gold. Available at: https://www. dentsply.com/content/dam/dentsply/pim/manufacturer/ Endodontics/Obturation/Gutta_Percha_Points/WaveOne_Gold_Gutta_Percha_Points/W1G_Brochure EN.pdf. Accessed Aug 2, 2017.

15. Ashraf F, Shankarappa P, Misra A, Sawhney A, Sridevi N, Singh A. A Stereomicroscopic Evaluation of Dentinal Cracks at Different Instrumentation Lengths by Using Different Rotary Files (ProTaper Universal, ProTaper Next, and HyFlex CM): An Ex Vivo Study. Scientifica (Cairo) 2016;2016:8379865. [CrossRef]

16. Kfir A, Elkes D, Pawar A, Weissman A, Tsesis I. Incidence of microcracks in maxillary first premolars after instrumentation with three different mechanized file systems: a comparative ex vivo study. Clin Oral Investig 2017;21:405-11.

17. Schneider SW. A comparison of canal preparations in straight and curved root canals. Oral Surg Oral Med Oral Pathol 1971;32:271-5. [CrossRef]

18. Capar ID, Arslan H, Akcay M, Uysal B. Effects of ProTaper Universal, ProTaper Next, and HyFlex instruments on crack formation in dentin. J Endod 2014;40:1482-4.
19. Liu R, Kaiwar A, Shemesh H, Wesselink PR, Hou B, Wu MK. Incidence of apical root cracks and apical dentinal detachments after canal preparation with hand and rotary files at different instrumentation lengths. J Endod 2013;39:129-32. [CrossRef]

20. Shemesh H, Bier CA, Wu MK, Tanomaru-Filho M, Wesselink PR. The effects of canal preparation and filling on the incidence of dentinal defects. Int Endod J 2009;42:20813. [CrossRef]

21. Tamse A. Vertical root fractures in endodontically treated teeth: diagnostic signs and clinical management. Endod Topics 2006;13:84-94. [CrossRef]

22. Yoldas O, Yilmaz S, Atakan G, Kuden C, Kasan Z. Dentinal microcrack formation during root canal preparations by different $\mathrm{NiTi}$ rotary instruments and the self-adjusting file. J Endod 2012;38:232-5. [CrossRef]

23. Shemesh H, van Soest G, Wu MK, Wesselink PR. Diagnosis of vertical root fractures with optical coherence tomography. J Endod 2008;34:739-42. [CrossRef]

24. De-Deus G, Silva EJ, Marins J, Souza E, Neves Ade A, Gonçalves Belladonna F, et al. Lack of causal relationship between dentinal microcracks and root canal preparation with reciprocation systems. J Endod 2014;40:1447-50.

25. Üstün Y, Topçuoğlu HS, Düzgün S, Kesim B. The effect of reciprocation versus rotational movement on the incidence of root defects during retreatment procedures. Int Endod J 2015;48:952-8. [CrossRef]

26. Topçuoğlu HS, Demirbuga S, Tuncay Ö, Pala K, Arslan $\mathrm{H}$, Karataş E. The effects of Mtwo, R-Endo, and D-RaCe retreatment instruments on the incidence of dentinal defects during the removal of root canal filling material. J En$\operatorname{dod} 2014 ; 40: 266-70$. [CrossRef]

27. Kuttler S, McLean A, Dorn S, Fischzang A. The impact of post space preparation with Gates-Glidden drills on residual dentin thickness in distal roots of mandibular molars. J Am Dent Assoc 2004;135:903-9. [CrossRef]

28. Sim TP, Knowles JC, Ng YL, Shelton J, Gulabivala K. Effect of sodium hypochlorite on mechanical properties of dentine and tooth surface strain. Int Endod J 2001;34:12032. [CrossRef]

29. Kim HC, Lee MH, Yum J, Versluis A, Lee CJ, Kim BM. Potential relationship between design of nickel-titanium rotary instruments and vertical root fracture. J Endod 2010;36:1195-9. [CrossRef]

30. Karataş E, Gündüz HA, Kırıcı DÖ, Arslan H, Topçu MÇ, Yeter KY. Dentinal crack formation during root canal preparations by the twisted file adaptive, ProTaper Next, ProTaper Universal, and WaveOne instruments. J Endod 2015;41:261-4. [CrossRef] 